\title{
Hongos anamorfos biodegradan los libros del Área Histórica de la Universidad Central del Ecuador (UCE)
}

\author{
(Anamorphous fungi biodegrade the books of the Historical Area from the \\ Central University of Ecuador (CUE))
}

\author{
Rodríguez-Segovia, M. A. ${ }^{*}$, Arguello-Hidalgo, S. J. ${ }^{1}$, Carrera-Castro, M. C. ${ }^{1}$ \\ ${ }^{1}$ Universidad Central del Ecuador, Facultad de Ciencias Biológicas, Quito-Ecuador. \\ *Autor para correspondencia: marcozeus24@gmail.com
}

RECIBIDO: 5 de octubre 2020

APROBADO: 20 de noviembre 2020

DOI: $10.22370 /$ bolmicol.2020.35.2.2592

Palabras claves: Biodegradación, hisopado, libros antiguos, mohos.

Keywords: Biodegradation, swabbing, old books, molds.

\section{RESUMEN}

Determinamos los géneros de hongos anamorfos que contaminan los libros del área de cuarentena y limpieza, dentro del Área Histórica de la Universidad Central del Ecuador (UCE). Realizamos un hisopado aleatorio a una muestra representativa de 50 de estos libros de acuerdo a una Tabla militarizada estándar. También hisopamos como muestra preferencial a 21 libros gravemente contaminados con hongos. Los hisopados tuvieron una superficie de $5 \times 5 \mathrm{~cm}$, friccionando en la pasta, el borde y el interior de estos libros. Las 213 muestras tomadas fueron inoculadas en medio de cultivo Agar Malta. Los medios fueron incubados a una temperatura de $28^{\circ} \mathrm{C}$ durante 7 días. Realizamos observaciones por microscopía a 40 y 100x además de usar literatura especializada para la identificación hasta el nivel de género de hongos anamorfos. Los géneros más abundantes en este estudio fueron Penicillium (80,2\%) y Mucor $(8,1 \%)$.

\begin{abstract}
We determined the genera of anamorphic fungi that contaminate the books in the quarantine and cleaning area, within the Historical Area of the Central University of Ecuador (CUE). We performed a random swab on a representative sample of 50 of these books according to a standard militarized Table. We also swabbed as a preferential sample 21 books seriously contaminated with fungi. The swabs had a surface area of $5 \times 5 \mathrm{~cm}$, rubbing on the paste, the edge and the interior of these books. The 213 samples taken were inoculated in Agar Malta culture medium. The media were incubated at a temperature of $28^{\circ} \mathrm{C}$ for 7 days. We made observations by microscopy at 40 and $100 x$ in addition to using specialized literature for the identification down to the genus level of anamorphic fungi. The most abundant genus in this study were Penicillium (80,2\%) and Mucor $(8,1 \%)$.
\end{abstract}


Hongos anamorfos biodegradan los libros del Área Histórica de la Universidad Central del Ecuador (UCE). - Rodríguez-Segovia, M. A.

\section{INTRODUCCIÓN}

En la ciudad de Quito (Ecuador), la biblioteca de la Universidad Central del Ecuador (UCE) posee un Área Histórica donde se guardan unos 40000 libros patrimoniales antiguos ${ }^{1}$, la colección tiene ejemplares depositados que datan de entre el año 1485 a 1960. Muchos de estos libros se han deteriorado con el paso del tiempo a causa de la contaminación con diversos agentes microbiológicos. Principalmente hongos, los cuales son los principales agentes que contaminan y dañan libros antiguos por procesos de biodegradación ${ }^{2,3}$. El tipo de hongo más común deteriorando libros antiguos son los denominados hongos anamorfos u hifomicetos ${ }^{4}$. Estos suelen formar mohos visibles como pequeñas máculas que incluyen micelios e hifas sobre las superficies de los libros ${ }^{2,5,6}$.

El moho provocado por hongos es un elemento dañino e indeseable para materiales históricos y contemporáneos en bibliotecas y museos ${ }^{4,5}$. Algunos de estos hongos pueden resultar peligrosos para trabajadores y restauradores de bibliotecas que trabajan con archivos muy antiguos ${ }^{4}$. Existen especies que son patógenos infecciosos para el ser humano e inclusive pueden producir reacciones alérgicas asociadas a la producción de micotoxinas ${ }^{4,7}$.

$\mathrm{Al}$ interior de una biblioteca el aire circundante puede estar cargado de esporas, que son el principal medio de colonización de hongos, estas pueden acumularse paulatinamente junto con el polvo y pasar a ser un reservorio potencial de ellas $^{1,4}$. Las esporas son capaces de sobrevivir en condiciones ambientales difíciles de poca humedad al interior de los libros ${ }^{4}$. En los libros se pueden formar nichos microclimáticos ideales para su desarrollo a causa de la condensación de pequeñas gotas de agua, falta de ventilación y la retención de humedad por materiales higroscópicos ${ }^{4}$.

Entre los factores que permiten la proliferación de hongos en libros antiguos se encuentran la humedad, aireación, temperatura y la composición de los libros ${ }^{2,5,6}$. Se conoce que en libros antiguos los hongos biodegradan tintas orgánicas y aditivos (encolantes, abrillantadores ópticos), apresto (almidón o proteína) y revestimientos, además de las fibras de celulosa $^{5}$. El deterioro de los libros ocurre cuando las estructuras hifales atraviesan sus materiales, ocasionando un tipo de corrosión ácida, degradación enzimática y destrucción mecánica $^{3,4}$. De este modo libros con un valor cultural incalculable se echan a perder por culpa de estos microorganismos ${ }^{2,3}$.

Dentro del Área Histórica de la UCE muchos libros con signos de biodegradación son separados de la colección y llevados a un área de cuarentena y limpieza para evitar la contaminación cruzada hacia otros libros. En este lugar se trabaja en su restauración y aplicación de tratamientos para evitar la proliferación de hongos. En algunos casos este procedimiento no es factible porque el deterioro ha sido demasiado grande y los libros se echan a perder. Actualmente existen unos 446 libros almacenados en el área de cuarentena. El propósito de esta Investigación fue determinar qué géneros de hongos estaban presentes en libros del área de cuarentena dentro del Área Histórica de la biblioteca de la UCE. Este trabajo se llevó a cabo en los Laboratorios de Micología Aplicada de la Facultad de Ingeniería Química de la UCE y el Laboratorio Químico y Microbiológico anexo al Área Histórica de la UCE. 


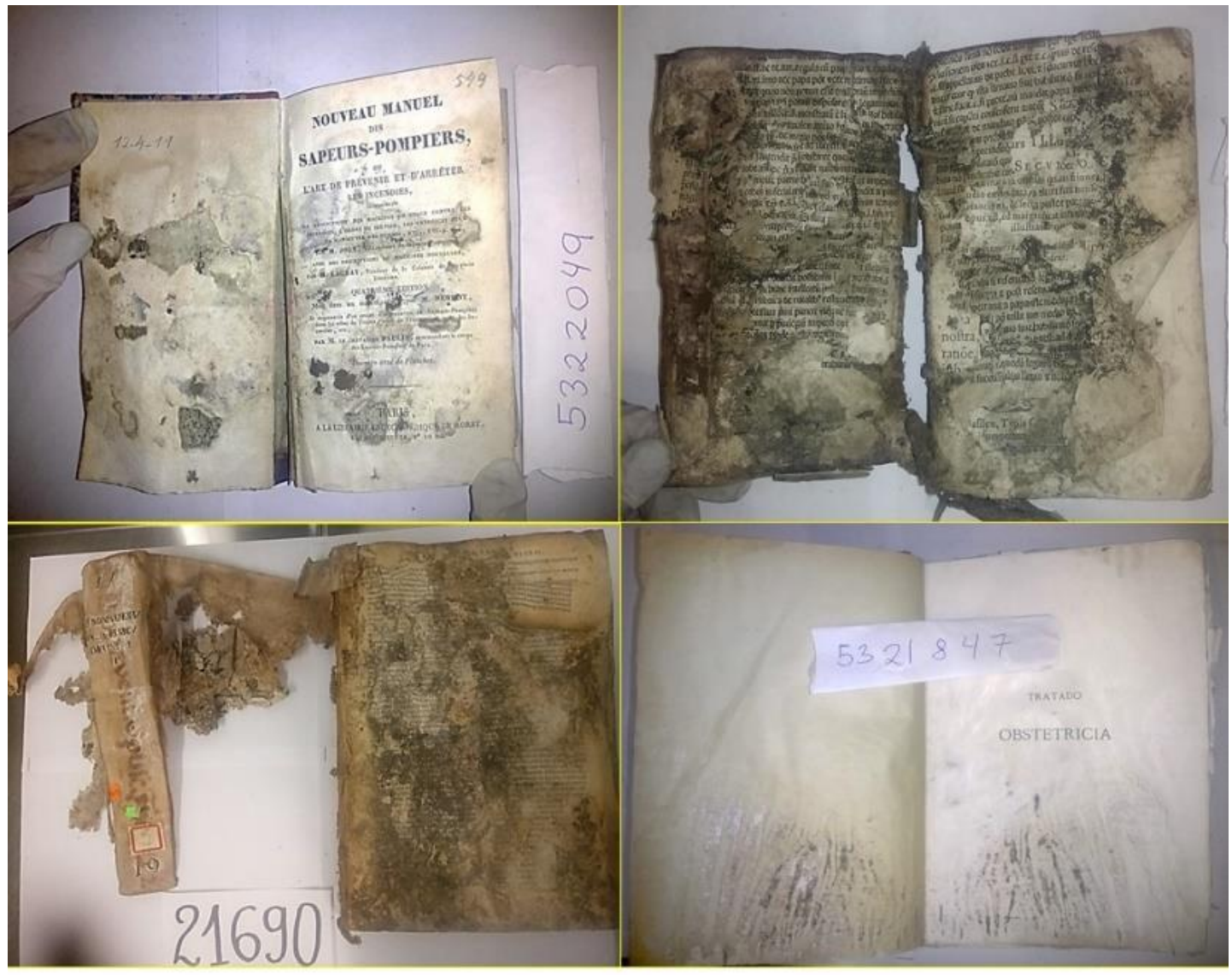

Figura 1. Biodegradación en libros del Área Histórica de la UCE. Note como el moho es visible a simple vista.

\section{MATERIALES Y MÉTODOS}

Obtuvimos una muestra representativa de los hongos presentes dentro del área de cuarentena dentro del Área Histórica de la UCE. Para ello nos basamos en una tabla militarizada estándar ${ }^{1}$. Esta tabla inspecciona muestras aleatorias de $\mathrm{n}$ unidades tomadas de lotes de tamaño $\mathrm{N}(\mathrm{N}=446)$ y que para un nivel de inspección $\mathrm{N}-2$, corresponde a un número de muestra de 50 libros, que fueron seleccionados aleatoriamente $^{1,2}$. Incrementamos esta muestra seleccionando de forma preferencial 21 libros que presentaban condiciones de contaminación y deterioro muy avanzadas. Estos libros estaban registrados en una lista digital dentro del área histórica que nos permitió ubicar los libros seleccionados dentro de sus estanterías. Para hisopar estos libros se utilizaron plantillas de papel desechables especialmente diseñadas para friccionar una superficie de $5 \times 5 \mathrm{~cm}$ en el interior de una cámara de flujo laminar (Figura 2) ${ }^{6}$. Hisopamos tres secciones de cada libro: la pasta, el borde y el interior (sumando un total de 213 muestras). Cada hisopado se sumergió en frascos de $5 \mathrm{ml}$ de solución salina al $0.9 \%$ para hidratar a los hongos durante 10 minutos $^{1,8}$ (tanto los hisopos como los frascos fueron autoclavados previamente para evitar contaminación). Posteriormente fueron inoculados en Medio de Cultivo Agar Malta y llevados a una incubadora a una temperatura de $28^{\circ} \mathrm{C}^{1}$. Se les dejó crecer por siete días y entonces se procedió a tomar muestras de las estructuras fúngicas con ayuda de cinta adhesiva transparente para extenderlas en portaobjetos ${ }^{19}$. Algunas preparaciones fueron teñidas con azul de lactofenol ${ }^{1}$. Se realizaron observaciones en microscopía a $40 \mathrm{x}$ y $100 \mathrm{x}$ y se utilizaron referencias taxonómicas para su identificación ${ }^{3-5,10}$. 


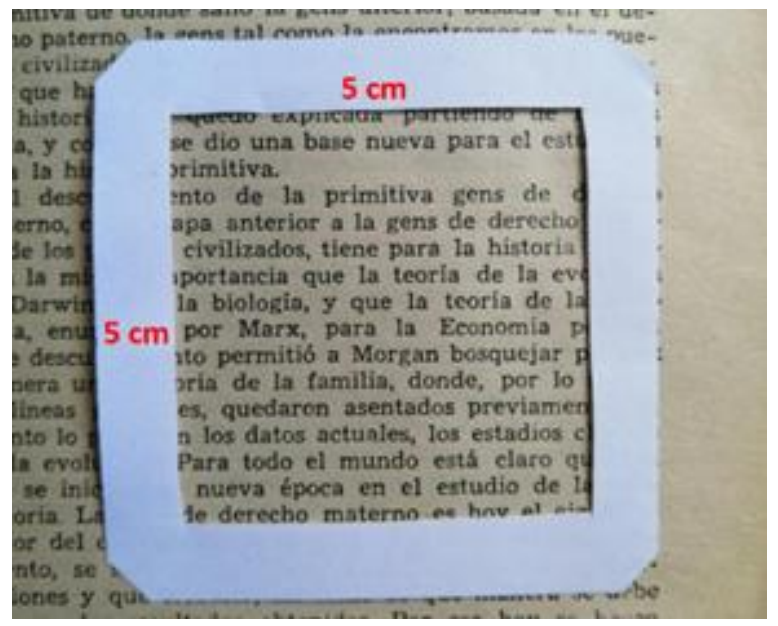

Figura 2. Plantilla de hisopado para superficies de $5 \times 5 \mathrm{~cm}$.

\section{RESULTADOS}

La mayoría de los hongos presentes en los libros del Área Histórica de la UCE son en su mayoría del género Penicillium $(80,2 \%)$ y Mucor $(8,1 \%)$, el resto de hongos registrados fueron encontrados en muy bajos porcentajes (Tabla 1 y Figura 3). Pudimos registrar una especie de levadura de la cual no logramos obtener una buena aproximación taxonómica (Figura 4). De los 213 cultivos realizados, 8 hisopados no resultaron en el desarrollo de hongos.

\begin{tabular}{lr}
\hline \multicolumn{2}{c}{ Tabla 1. Géneros de hongos encontrados en libros del } \\
Área Histórica de la UCE \\
\hline Géneros & Porcentaje \\
\hline Penicillium & $80.2 \%$ \\
Mucor & $8.1 \%$ \\
Chaetomium & $3.6 \%$ \\
Aspergillus & $3.2 \%$ \\
Trichoderma & $2.7 \%$ \\
Cladosporium & $0.9 \%$ \\
Scopulariopsis & $0.5 \%$ \\
Rhizopus & $0.5 \%$ \\
Levadura & $0.5 \%$ \\
\hline Sumatoria & $100 \%$ \\
\hline
\end{tabular}


Hongos anamorfos biodegradan los libros del Área Histórica de la Universidad Central del Ecuador (UCE). - Rodríguez-Segovia, M. A.

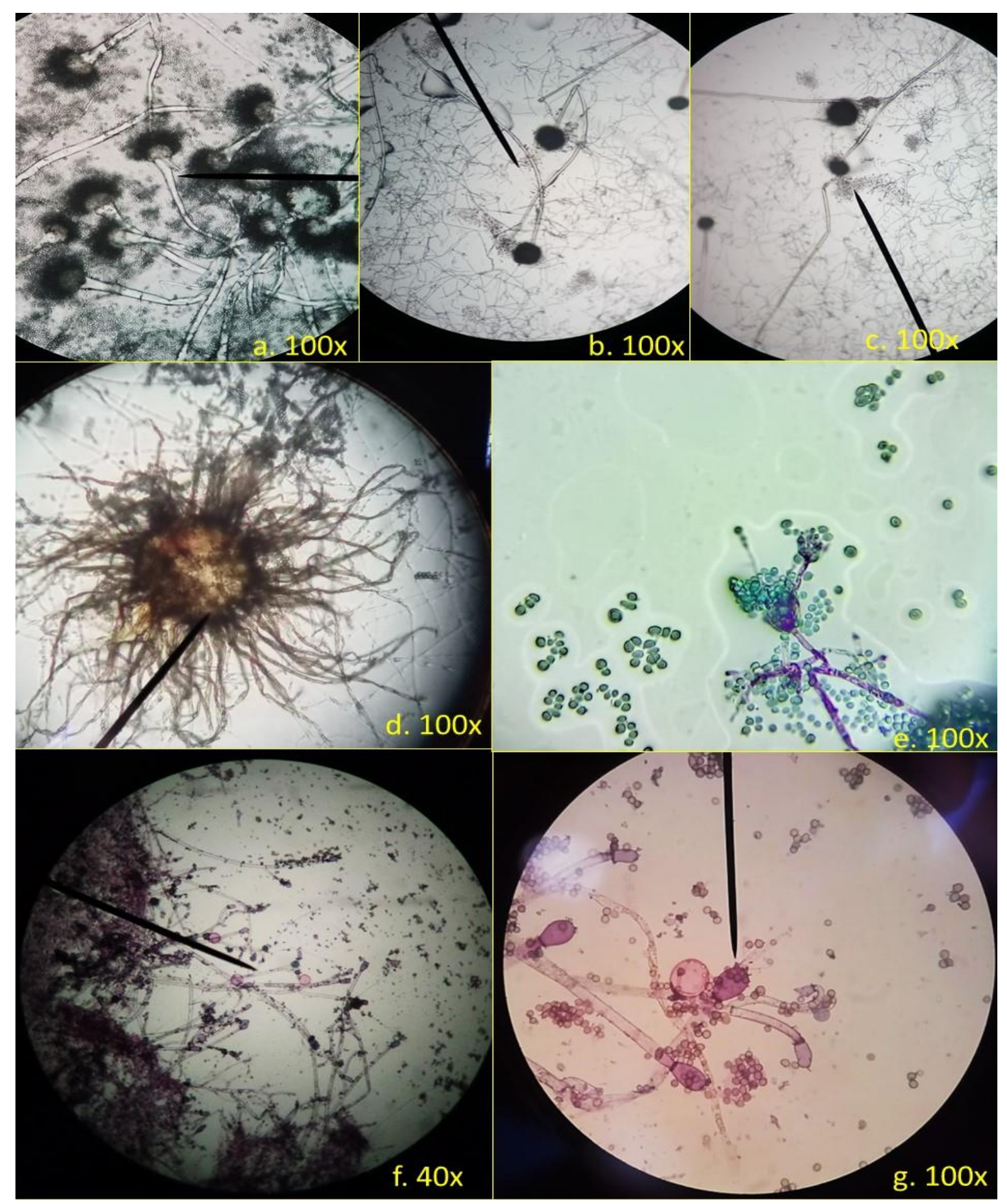

Figura 3. Algunas fotografías de los hongos encontrados: a. Aspergillus. b y c. Rizhopus. d. Chaetomium. e. Penicillium. f y g. Mucor. 


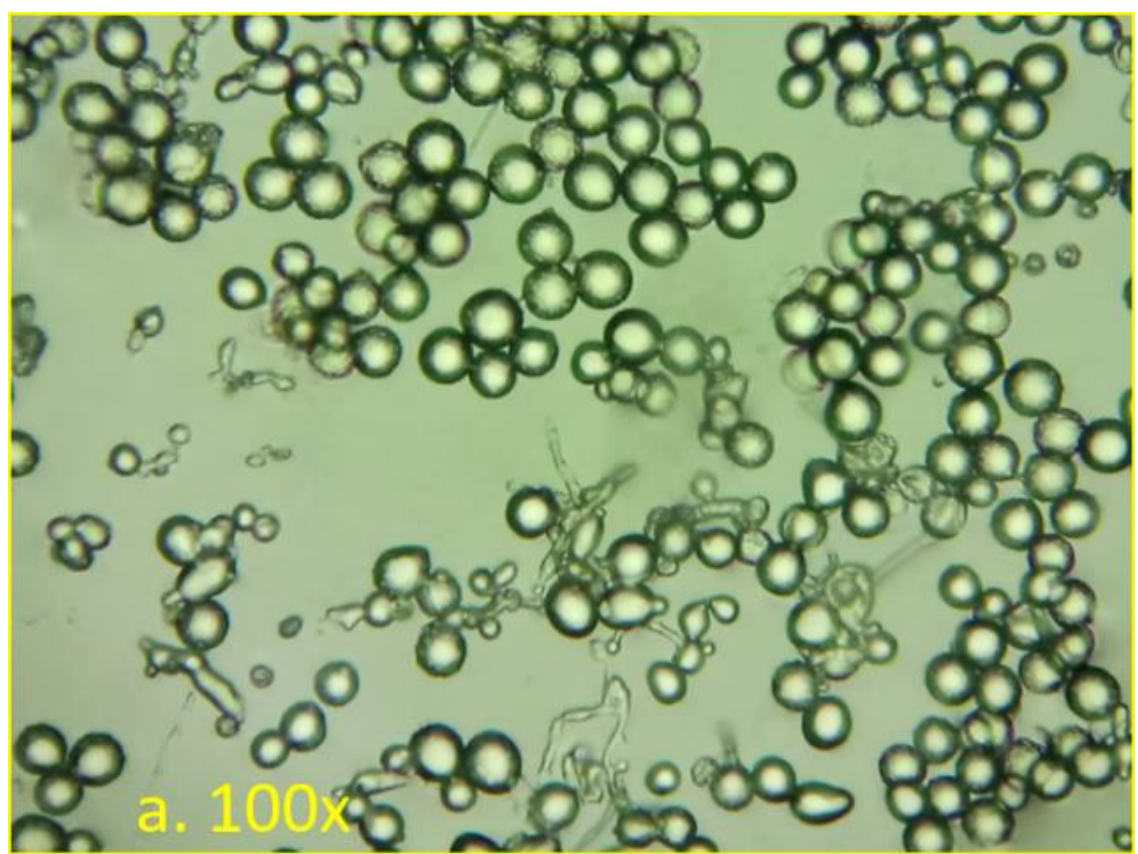

Figura 4. Una levadura.

\section{DISCUSIÓN}

En años anteriores un estudio similar al nuestro y realizado también dentro del Área Histórica de la UCE encontró únicamente a los géneros Penicillium y Aspergillus, pero no a los géneros Cladosporium, Rizhopus, Trichoderma, Scopulariopsis, Mucor, y una Levadura². Atribuimos este hecho a la asignación muestral que tuvo nuestro trabajo. En general todos estos géneros son comunes de encontrar deteriorando materiales en bibliotecas y museos antiguos ${ }^{4}$.

Diversos estudios mencionan que los géneros Penicillium, Aspergillus y Cladosporium, tienen una gran afinidad por ambientes osmóticos y son una amenaza común para la preservación de objetos patrimoniales en museos y bibliotecas ${ }^{4-}$ 6. Al parecer las condiciones ambientales al interior del Área Histórica de la biblioteca de la UCE permitieron la proliferación de este tipo de hongos.

Aunque la identificación de hongos basados en caracteres morfológicos todavía es muy usada en la restauración de museos, es necesario reemplazarla por métodos más confiables basados en la identificación de secuencias de ADN que pueden dar una mejor idea de la diversidad fúngica de un lugar y la aplicación de medidas para su control ${ }^{4}$. La dificultad en identificar la levadura encontrada es un buen ejemplo de esta necesidad.

Por último, vale la pena considerar que especies de los géneros Aspergillus, Penicillium y Chaetomium han sido reportadas como agentes infecciosos para el ser humano, estas son capaces de ocasionar infecciones sistémicas graves que sumadas a sus micotoxinas pueden acarrear un posible riesgo de salud para los trabajadores del Área Histórica de la UCE ${ }^{4,7}$. En este sentido una revisión más profunda de las especies es recomendable.

\section{CONCLUSIONES}

Los hongos encontrados en este estudio son una potencial amenaza por su capacidad de biodegradación para la conservación del 
patrimonio del Área Histórica de la UCE. El esfuerzo de este trabajo logró documentar una mayor riqueza de géneros de hongos en comparación a estudios previos. Los géneros determinados aquí también se han hallado en otros estudios. Es posible que estos hongos también representen un posible peligro para la salud de los trabajadores del Área Histórica de la UCE.

\section{AGRADECIMIENTOS}

Queremos agradecer al Doctor Paúl Gamboa Trujillo y al Ingeniero Ariel Vizcaíno por el apoyo brindado y el acceso hacia los laboratorios y Área Histórica de la UCE.

\section{REFERENCIAS}

1. Campués M. Formulación de una solución anfúngica para el tratamiento de libros del área histórica de La Universidad Central Del Ecuador [Pregrado]. Universidad Central del Ecuador 2016.

2. Campués M, Naranjo L, Santamaríaaguirre J, Sanmartín N, Yanez T, Bonilla P. Formulación de una solución antifúngica para la Preservación del Archivo Histórico de la Universidad Central del Ecuador. Quim Cent. 2017;6(01):3-9.

3. Villalba LS, Mikán JF, Sánchez J. Actividades hidrolíticas y caracterización isoenzimática de poblaciones microbianas aisladas del patrimonio documental del Archivo General de Colombia. Nova 2004;2(2):50.
4. Sterflinger K, Pinzari F. The revenge of time: fungal deterioration of cultural heritage with particular reference to books, paper and parchment. Environ Microbiol. $2012 ; 14(3): 559-566$.

5. Giraldo-Castrillón M, Torres-Gonzáles C, Díaz-Ortiz JE. Aislamiento de hongos celulolíticos causantes del biodeterioro de la Biblioteca Central de la Universidad del Valle (Cali-Colombia). Rev Mex Mic. 2009;29.

6. Morales R, Chalán R. Estudio de las condiciones de trabajo en bibliotecas de la ciudad de Quito y la exposición de sus trabajadores a hongos. Enfoque UTE. 2017;8(2):94.

7. Jarvis BB, Miller JD. Mycotoxins as harmful indoor air contaminants. Appl Microbiol Biotechnol. 2005;66(4):367-72.

8. Infante VV, Cano AM, Valdovinos HM, Macías AE, Álvarez JA. Solución salina como medio de cultivo desde el punto de vista de las bacterias nosocomiales. Rev Investig clínica. 2012;64, Núm 2:120-5.

9. Peña R, Paéz J. Guía para la observación de hongos fitopatógenos. [Internet]. Universidad Pedagógica y Tecnológica de ColombiaFitopatología General. 2020 [Citado 25 Jun 2020]. $\quad$ p. $6 . \quad$ Disponible en :https://virtual.uptc.edu.co/ova/fito/archivo/g uia7.pdf

10. Barnett HL, Hunter BB. Ilustrated Genera of Imperfect Fungi. 4th ed. SERBIULA; 1987. 